\title{
RELATOS DE JOVENS DEFICIENTES MENTAIS SOBRE A SEXUALIDADE ATRAVÉS DE DIFERENTES ESTRATÉGIAS ${ }^{1}$
}

\author{
Ana Cláudia Bortolozzi Maia ${ }^{2}$ \\ Denise do Amaral Camossa \\ Universidade Estadual Paulista - Bauru
}

\begin{abstract}
RESUMO: O objetivo deste trabalho consistiu em utilizar estratégias para obter e analisar relatos sobre sexualidade de cinco jovens, ambos os sexos, com deficiência mental, por diferentes procedimentos metodológicos: 1) Desenho da Figura Humana; 2) Apresentação de bonecos da família sexuada; 3) Apresentação das pranchas dos temas: namoro, casamento, masturbação, jogos sexuais, menstruação, relação sexual, gravidez, parto, amamentação e abuso sexual. Observou-se que os jovens: a) têm noção de identidade e papéis sexuais; b) diferenciam e nomeiam órgãos sexuais humanos, especialmente o órgão sexual masculino adulto; c) apesar de saberem nomeá-los, nem todos sabem sua função; d) com frases curtas e objetivas os jovens mostraram os conceitos sobre os diferentes temas apresentados. As estratégias utilizadas foram eficientes para incentivar 0 relato de jovens com limitação intelectual em temas complexos como a sexualidade.
\end{abstract}

Palavras-chave: sexualidade, deficiência mental, recursos metodológicos

\section{REPORTS OF YOUTHS WITH MENTAL DEFICIENCY ABOUT THE SEXUALITY BY DIFFERENT STRATEGIES}

\begin{abstract}
The aim of this study was to use strategies to obtain and analyze reports about sexuality of five young, both sexes, with mental deficiency, by different methodological procedures: 1) The Draw of the Human body; 2) puppets of the sex family; 3 ) boards of the themes: date, marriage, masturbation, sexual games, period, sexual relationship, pregnancy, childbirth, breast-feeding and sexual abuse. It was observed that the youths: a) have notion about sexually identity and sexual rows; b) name and differentiate human sexual organs, especially the adult sexual male organ; c) in spite of knowing how to name them, nor all know its function; d) with short sentences and lenses the youths showed the concepts of the different presented themes. The strategies used were efficient to motivate the youths' report with intellectual limitation in complex themes as the sexuality.
\end{abstract}

Key-words: sexuality, mental deficiency, methodological resources

A sexualidade da pessoa com deficiência mental é inegável, pois, como atributo humano, ela é inerente a qualquer pessoa a despeito de limitações incapacitantes de cunho biológico, psicológico ou social.

Ainda que o grau do retardo possa influenciar sobremaneira a capacidade de manifestar e vivenciár vínculos afetivo-sexuais, a maior problemática do deficiente mental não está na sua condição biológica ou

\footnotetext{
${ }^{1}$ Artigo recebido para publicação em 07/2002; aceito em 11/2002 2 Endereço para correspondência: Ana Cláudia Bortolozzi Maia, Departamento de Psicologia, Faculdade de Ciências, UNESP, Av. Eng. Edmundo Carrijo Coube $\mathbf{s} / \mathbf{n}^{\circ}$, Vargem Limpa, Bauru, SP, Cep 17033-360, E-mail bortolozzimaia@uol.com.br
}

nos déficits intelectuais, mas sim na dificuldade da sociedade em lidar com a manifestação e com a educação sexual da pessoa deficiente mental (Denari, 1997; Gale, 1989; Gherpelli, 1995; Glat, 1992; Glat \& Freitas, 1996; Maia, 2001a; Pinel, 1999). Acrescente-se que, na grande maioria dos chamados deficientes mentais no Brasil ocorre um comprometimento leve ou moderado.

A esse respeito Maia (2001a) afirma:

"A conduta sexual, as relações interpessoais e a convivência com parceiros são freqüentemente relacionadas ao 
grau do retardo. Comportamentos da sexualidade - dos mais simples como abraços, beijos e palavras aos mais intimos como masturbação solitária, masturbação em grupo e relação sexual, parecem sempre processos complexos quando manifestados por uma pessoa com deficiência mental. Ou seja, comportamentos tolerados em algumas pessoas tornam-se, seguindo um preconceito social, aberrações elou desvios na pessoa deficiente mental, o que reforça a repressão e a sua problemática" (Maia, 2001a, p.39).

Segundo Gale (1989) as barreiras que podem limitar a vivência da sexualidade do deficiente mental seriam físicas, psicológicas e sociais. São barreiras físicas a falta de aptidão verbal, de locomoção, de higiene pessoal e maneirismos; as barreiras psicológicas seriam tédio, isolamento, depressão e baixa auto-estima; as barreiras sociais estariam no isolamento, falta de convívio entre amigos, discriminação e preconceitos sociais.

Outros aspectos sociais que se refletem no desenvolvimento psicossexual da pessoa com deficiência mental são, especialmente, a imagem corporal, a auto-estima, a manifestação da identidade e do papel sexual e ainda a vulnerabilidade à exploração sexual por terceiros (Gherpelli, 1995; Maia, 2001a; Pinel, 1999). França Ribeiro (1995) completa, afirmando que para resgatar os aspectos sexuais, muitas vezes comprometidos pela sociedade, é preciso observar como o processo de educação sexual tem permitido à pessoa com deficiência mental dar e receber afeto e exteriorizar as pulsões libidinais comuns a todos desde o nascimento. A educação sexual, neste caso, está sendo considerada como um processo amplo que permeia toda a vida da pessoa ao longo de seu desenvolvimento, incluindo a aprendizagem de regras sociais em relação à sexualidade (Cavalcanti, 1993; Maia, 2001b; Ribeiro, 1990; Vitiello, 1995; Werebe, 1977).

Iniciando pelo comprometimento da imagem corporal, tem-se que ele está relacionado diretamente às dificuldades de socialização e de construção da identidade social, o que pode ocasionar bloqueios emocionais e carências afetivas que estimulam os deficientes a desenvolverem crenças e expectativas falsas e ainda, sentimentos de inferioridade, frustração e de baixa estima além de uma auto-imagem distorcida (Pinel, 1999).

Já a questão da identidade sexual, vista como o sentimento e a auto percepção que as pessoas têm em relação ao gênero e se expressam como 'sentirse homem' ou 'sentir-se mulher', ocorre por volta dos 3 anos de idade independentemente da orientação afetivo-sexual homossexual ou heterossexual desenvolvida e formalizada na adolescência e idade adulta. Os papéis sexuais são manifestados pelo conjunto de expressões sociais como 'feminilidade' e 'masculinidade', crenças, sentimentos, expectativas e atitudes culturalmente determinados (Cavalcanti, 1990; Duarte, 1995; Maia, 2001b; Mead, 1988; Money \& Tucker, 1975; Paiva, 1989; Whitaker, 1989). Desde o nascimento os papéis sexuais são exibidos às crianças no processo de educação sexual e elas demonstram a sua assimilação nas brincadeiras e atividades gerais.

A identidade sexual e a manifestação dos papéis sexuais - como essa identidade é expressa socialmente - estão diretamente ligados às expectativas sociais relacionadas aos diversos comportamentos sexuais considerados desejáveis e adequados, presentes antes do nascimento. Em geral, tais expectativas mantêm certa unicidade ou constância. No desenvolvimento sexual da pessoa com deficiência mental este processo pode estar comprometido, pois, na maioria das vezes, a criança cresce segregada de um convívio social mais amplo e as poucas informações que recebe acabam sendo veiculadas genericamente e assimiladas de forma deturpada. Além disso, a construção da identidade sexual da pessoa com deficiência mental fica prejudicada e agravada pela manifestação de papéis sexuais nem sempre compatíveis com sua identidade de gênero ou socialmente aceitos (Gherpelli, 1995; Pinel, 1999).

A sexualidade de uma pessoa deficiente mental vêm sendo marcada por dois grandes mitos (crenças sociais): primeiro que ela é 'assexuada' e, segundo, que é 'hipersexuada' (Amaral, 1994; Denari, 1997; França Ribeiro, 1995; Giammi \& D'Allones, 1984; Glat, 1992; Glat \& Freitas, 1996; Lipp, 1981; Maia, 2001a; Pinel, 1999). Tais mitos desconsideram que as necessidades, desejos e capacidades sexuais 
dos deficientes mentais são iguais aos das pessoas não deficientes, embora no trato social esta manifestação possa ser, simbolicamente, registrada como diferente.

Em ambos os casos, o dogma da assexualidade - a idéia de que a pessoa com deficiência mental é uma criança, angelical e desprovida de sexo - quanto o da hipersexualidade - de que ela é uma aberração, um desvio, dotada de uma sexualidade exagerada, agressiva e animalesca - acabam reforçando atitudes em relação ao deficiente mental que levam ao isolamento, à segregação e à ignorância sobre os aspectos de sua sexualidade. Em decorrência dessas concepções errôneas a orientação sexual é negligenciada com relação a esta população.

Acredita-se que as pessoas com deficiência mental, em geral, passam a vida recebendo uma educação sexual familiar permeada de mitos e preconceitos, sem disporem de uma orientação formaliza$\mathrm{da}$, pertinente, que permitiria extrapolar a repressão e a negação de sua sexualidade.

Reche (1994) investigou as teorias sexuais infantis em 17 adolescentes com deficiência mental sendo sete deles de grau leve e dez de grau moderado. Essas teorias, constatadas pela psicanálise, dizem respeito às crenças, próprias da criança, sobre o nascimento, a fecundação e as diferenças entre sexos e devem-se, basicamente, a duas influências, uma relacionada ao desenvolvimento psicossexual e outra à consequiência das pressões educacionais. A autora trabalhou com a hipótese de que as teorias sexuais dos adolescentes com deficiência mental seriam muito semelhantes às de adolescentes não deficientes, ainda que o desenvolvimento cognitivo dessa população estivesse comprometido por um precário raciocínio lógi$\mathrm{co}$, correspondendo a um nível pré-operacional, mesmo que, em outras situações educacionais eles apresentassem estágios cognitivos inferiores. A autora concluiu que as teorias sexuais dos deficientes mentais foram muito semelhantes às apresentadas por crianças normais, que as competências observadas nos psicodiagnósticos não corresponderam exatamente à capacidade de formulação dessas teorias e ainda que não foram observadas correlações entre as classificações dos Quocientes de Inteligência (QIs) e as teorias sexuais infantis elaboradas e verbalizadas nos jovens estudados.
No estudo relatado por Glat (1992), a autora observou que é um estereótipo associar aos deficientes mentais uma incapacidade de analisar sua própria vida e de expressar suas emoções, desejos e sentimentos. Neste sentido, seu estudo procurou investigar com jovens deficientes mentais de ambos os sexos alguns assuntos sobre a sexualidade, através de um roteiro de entrevista adaptado à linguagem do participante. Glat (1992) verificou que havia pouca interação social e que as amizades e relacionamentos existentes eram entre colegas da mesma instituição, fato ainda mais freqüente tratando-se das mulheres. As experiências de namoro relatadas por eles limitavam-se a contatos físicos restritos e a algum grau de intimidade leve, sem relações sexuais. Os conhecimentos sobre sexualidade, funções corporais, reprodução, nascimento e métodos anticoncepcionais eram precários e superficiais. As respostas dos jovens foram bastante restritas, pouco detalhadas e descritivas, chegando ao absurdo. Para ela, a pouca informação a respeito de aspectos básicos da sexualidade, como o funcionamento do próprio corpo, reflete uma educação repressora, proibitiva, omissa e um acúmulo de informações mal esclarecidas e deturpadas; e "a infantilização e o isolamento social, e não seu quociente intelectual ou problema neurológico que os impedem de gozarem de uma vida amorosa plena e satisfatória" (p.72). Além disso, Glat (1992), FrançaRibeiro (2001) e Maia (1999) ressaltam que poucos estudos procuram ouvir o que os deficientes mentais têm a dizer sobre sua sexualidade.

Num estudo sobre a identidade e papéis sexuais observados, Maia (2001c), a partir do relato de jovens com deficiência mental, mostrou que eles foram capazes de reconhecer sua identidade sexual e também reproduziram os papéis sexuais socialmente vigentes na cultura, isto é, acreditavam que as diferenças da masculinidade e feminilidade estavam relacionadas a vestimenta e adornos - como usar saia, calça comprida, pintar o cabelo - a atividades - como cozinhar, dirigir, jogar futebol, trabalhar fora, ir para o exército, brincar de carrinho e boneca. Apenas um rapaz referiu-se à questão anatômica para justificar a diferença, afirmando que os homens tinham pênis. No geral, predominaram os comentários comuns em nosso meio. A conclusão, neste caso, é que as pessoas com deficiência mental estão sujeitas às mes- 
mas influências da cultura, ou seja, aos processos de educação sexual e repressão, tendo a autora afirmado que se encontra "a influência social nos padrões de socialização diferenciada entre os sexos também na população deficiente mental" (p.625).

As manifestações sexuais das pessoas deficientes mentais são entendidas pela sociedade, com frequência, como inaceitáveis, mas é importante alertar que quase todas essas manifestações 'perversas' são frutos da ignorância e da falta de treinamento e que a própria sociedade não respaldou nem garantiu ao deficiente uma educação condizente. A impulsividade, assim como a dificuldade de discriminar os comportamentos adequados, complica o processo de aprendizagem social e sexual no deficiente mental, mas não a torna impossível. A sociedade reconhece que a aprendizagem para essas pessoas depende de mensagens transmitidas de forma simples, concretas e repetidas, o que não seria diferente numa sistematização de instruções voltadas para uma orientação sexual dirigida ao público em geral (França Ribeiro, 1995; Glat, 1992; Pinel, 1999).

A formação de conceitos e o aprendizado sobre os temas gerais da sexualidade como identidade e papéis sexuais, nomes e funções das partes genitais do corpo humano e os assuntos complexos como namoro, casamento, nascimento, amamentação, masturbação, jogos sexuais infantis, tanto para jovens em geral como para os com deficiência mental, decorrem de uma educação sexual que é informal e constante. No caso da sexualidade do deficiente mental, há autores (Assumpção Júnior \& Sprovieri, 1993; Glat, 1992). afirmąndo que ela dependeria da estruturação de esquemas educacionais que proporcionassem condições adequadas para a sua expressão, pois ele é, em última instância, uma pessoa íntegra em sua totalidade e não é deficiente sob o ponto de vista erótico e sexual A esse respeito, Glat (1992) diz que: “.... pessoas ditas 'excepcionais' não são necessariamente excepcionais em seus impulsos e desejos sexuais. Elas têm necessidades normais, experiências normais e emoções humanas normais" (p.66).

Maia (2001a) coloca que os conhecimentos científicos sobre as concepções da sexualidade ainda são escassos e que seria fundamental valer-se de pesquisas voltadas para o relato de profissionais, familiares e pessoas com deficiência mental. Neste sentido, de acordo com a literatura apresentada, este estudo teve como objetivo contribuir para o esclarecimento de questões sexuais na vida da pessoa com deficiência, partindo do relato de jovens deficientes sobre alguns aspectos da sexualidade, utilizando-se de propostas metodológicas alternativas, visando investigar a sua noção de identidade e de papéis sexuais, a capacidade de nomear e identificar funções dos órgãos genitais nos dois gêneros e finalmente, os conceitos sobre temas como namoro, casamento, gravidez, parto, amamentação, masturbação, jogos sexuais e abuso sexual.

\section{Método}

\section{Participantes}

Participaram da pesquisa cinco jovens com diagnóstico de deficiência mental, grau leve, com idade cronológica entre 13 e 28 anos. A Tabela 1 mostra sua distribuição quanto ao gênero e à idade.

Tabela 1: Distribuição dos participantes quanto ao gênero e a idade

\begin{tabular}{clc}
\hline Participantes & \multicolumn{1}{c}{ Sexo } & Idade Cronológica \\
P1 & Masculino & 28 anos \\
P2 & Feminino & 13 anos \\
P3 & Feminino & 23 anos \\
P4 & Masculino & 16 anos \\
P5 & Feminino & 22 anos \\
\hline
\end{tabular}

Todos os jovens freqüentavam a Clínica-Escola de Psicologia de uma universidade pública em cidade do interior paulista.

\section{Materiais}

Para a coleta de dados foram utilizados os seguintes materiais:

Um Roteiro de Entrevista composto por quatro etapas, incluindo identificação, Desenho da Figura Humana e família, tarefa com os bonecos da Família Sexuada, descrição das Pranchas Ilustrativas;

- Uma Família Sexuada composta de quatro bonecos feitos de pano. Dois dos bonecos eram 
adultos de 20 centímetros de altura: uma mulher com vulva, pêlos pubianos e mamas e um homem com pênis, dois sacos escrotais e pêlos pubianos. Os outros dois bonecos eram crianças de 10 centímetros de altura: uma menina que apresentava vulva e mamas não desenvolvidas e um menino com um pênis $e$ dois sacos escrotais. Nenhum dos bonecos que representavam crianças tinha pêlos pubianos; Pranchas ilustrativas, com fotos e desenhos de cenas de dez temas: namoro, casamento, menstruação, masturbação, jogos sexuais, relação sexual, gravidez, parto, amamentação, abuso sexual; Para alguns havia duas pranchas para garantir maior representação da cena. Exemplos: no tema da amamentação havia uma cena de um bebê mamando na mamadeira e outro mamando na mama da mãe; no do parto havia uma cena de um parto normal e de um parto tipo cesariana. As pranchas foram feitas a partir de ilustrações diversas, escaneadas pelo computador e padronizadas no mesmo formato e tamanho, colocadas uma a uma em folhas de plástico, numa pasta apropriada.

Folhas tipo sulfite branca, tamanho A4, lápis e giz de cera coloridos e lápis preto.

\section{Procedimento}

As sessões de coleta de dados foram realizadas após a autorização dos pais, em uma sala reservada na própria clinica escola em que os participantes freqüentavam, que tinha acomodações adequadas e estava livre de ruídos. Cada cliente respondeu à entrevista individualmente, com horário previamente agendado e a duração da tarefa foi, em média de 50 minutos.

Inicialmente o participante era informado sobre o tema da conversa e, após rapport inicial, a experimentadora lia as instruções das tarefas de forma clara e pausada para que pudesse ser compreendida. Os procedimentos da aplicação da entrevista podem ser descritos em três momentos:

a) Desenho da Figura Humana e família Cada participante recebeu uma folha de sulfite em branco, tendo sobre a mesa 1 lápis preto e 12 lápis coloridos. A instrução era para que desenhasse uma pessoa da forma como quisesse; cumprida a tarefa, eram feitas algumas perguntas sobre a pessoa desenhada. A seguir, outra folha em branco era entregue e repetia-se a instrução, acrescentando que o sexo da pessoa do novo desenho deveria ser o oposto do primeiro, havendo depois um diálogo sobre ele. Por último, era entregue ao participante outra folha, com a instrução para que desenhasse sua família, seguindo-se perguntas referentes à família.

b) Família sexuada de bonecos Cumprida essa tarefa, a experimentadora colocava a família de bonecos sobre a mesa e pedia a cada participante que os despisse. Depois, apontava para cada boneco, separadamente, e fia perguntas referentes ao corpo humano de homens e mulheres.

c) Relato verbal sobre temas da sexualidade a partir das pranchas ilustrativas.

As pranchas com os dez temas já especificados eram mostradas uma a uma, sendo que cada uma ficava exposta enquanto se perguntava ao participante o que ele achava que estava acontecendo na cena apresentada, deixando-o livre para quaisquer verbalizações sobre o tema.

\section{Resultados}

Os dados foram analisados quantitativa e qualitativamente quando possível, dependendo da natureza e da complexidade das respostas. ${ }^{1}$

Os resultados são apresentados seguindo as três etapas do roteiro da entrevista:

\section{1) Desenho da Figura Humana e familia}

Investigando a questão da identidade sexual e o conceito de papéis sexuais, todos os participantes desenharam primeiramente uma pessoa com sexo igual ao deles e demonstraram noção de sua própria identidade sexual, isto é, reconhecem-se como homens ou como mulheres.

Sobre as concepções de 'ser mulher', observou-se que, em geral, os participantes atribuíram à condição feminina os aspectos físicos não genitais e

\footnotetext{
1 Vale lembrar que embora a casuística do estudo seja pequena, considera-se relevante investigar a maneira pela qual os jovens com deficiência mental expressam seus relatos sobre sexualidade a partir das atividades interativas descritas nesta entrevista.
} 
os comportamentais (papéis sexuais). P1M e P5F relacionaram o que é ser mulher com a aparência física "porque é bonita e tem cabelo comprido" e "saia, cabelo mais grande", respectivamente. $\mathrm{P} 2 \mathrm{~F}$ atribuiu a feminilidade à diferença: "porque é diferente do homem", $\mathrm{P} 3 \mathrm{~F}$ às questões religiosas: "porque Deus fez ela mulher" e P4M deu uma resposta sem sentido: "porque o pai puxou ela".

O que cada figura desenhada tinha de mulher, P3F, P4M e P5F indicaram partes do corpo: "pé", "rosto" e "tem pescoço mais fino", respectivamente. P1M falou apenas que "é diferente do homem" e P2F aontou "o vestido".

Os participantes consideram, em geral, bom ser mulher e as justificativas versaram sobre os papéis sexuais:

"Bom, porque se troca, se pinta, passa batom" (PIM)

"Bom, porque a menina é quietinha, não é como menino que xinga e mexe com as meninas" $(P 2 F)$;

"Gostoso, porque é tranqüila e homem não" (P3F)

"Mais ou menos, porque não respeita as pessoas" (P4M)

"Bom, a gente não tem muitas coisas pra fazer, temos filhos, cuidar da casa" (P5F).

Sobre as concepções de 'ser homem', observou-se que os P1M e P5F atribuíram à condição masculina alguns estereótipos: "porque é alto, diferente de mulher, tem mais responsabilidade", "anda meio jogando o corpo, jeito de machão", respectivamente. $\mathrm{P} 2 \mathrm{~F}$ e $\mathrm{P} 3 \mathrm{~F}$ falaram da diferença: "porque é diferente", "porque é diferente da mulher". E P4M deu uma resposta geral: "porque viveu assim".

Quanto ao que cada figura tinha de homem, três jovens indicaram partes físicas: "cabelo" $(P I M)$, "rosto" (P3F) e "cara de bonito" (P4M). P2F disse "não sei" e P5F "aqui no desenho, nada".

Os participantes consideram, em geral, bom ser homem e as justificativas versaram sobre os papéis sexuais e comportamentos:

"Bom, porque tem que ter responsabilidade" (PIM)

"Ruim, porque são chatos" $(P 2 F)$

"Nunca fui. Acho que é legal, porque pode casar e ter filhos" (P3F)

"Bom, respeita as pessoas" (P4M)

"Para eles acho que é bom. Eles gostam de mulher, ficam com uma e outra" (P5F).

\section{2) Familia sexuada de bonecos: investigação dos nomes e funções dos órgãos genitais externos}

Diante da família sexuada de bonecos, dois participantes apontaram para a menina e a mulher adulta quando perguntados sobre quais bonecos eram mulheres e dois somente para a mulher adulta; indagados sobre quais eram homens, 2 indicaram o menino e três o homem adulto. Quando se questionou o que diferenciava as mulheres dos homens os resultados foram: "ao corpo", "órgão sexual" (3), ao "tamanho dos bonecos" (1) e "uma obra de Deus" (1).

Observou, por outro lado que os jovens souberam nomear corretamente, especialmente quando tratava-se do pênis de um homem adulto, o órgão genital masculino, como pode ser visto na Tabela 2.

Tabela 2: Respostas dos participantes quanto à nomeação de partes do corpo de bonecos da família sexuada.

\begin{tabular}{l|c|c}
\hline $\begin{array}{l}\text { Avaliação das Respostas } \\
\text { Partes do Corpo } \\
\text { Humano dos bonecos }\end{array}$ & $\begin{array}{c}\text { CORRETAS } \\
\text { Nomearam } \\
\text { Corretamente }\end{array}$ & $\begin{array}{c}\text { INCORRETAS } \\
\text { Não nomearam } \\
\text { ("não sei"; "não } \\
\text { lembro") }\end{array}$ \\
\hline Órgão sexual da menina: vulva & 2 & 3 \\
\hline Seios (mamas) da mulher adulta & 3 & 2 \\
\hline Orgão sexual da mulher adulta: vulva & 2 & 3 \\
\hline Orgão sexual do menino: pênis & 4 & 1 \\
\hline Órgão sexual do homem adulto: pênis & 4 & 1 \\
\hline Sacos Escrotais do homem adulto & 3 & 2 \\
\hline
\end{tabular}


No que se refere à função dos órgãos sexuais femininos, as respostas foram relacionadas à excreção (eliminação da urina), embora alguns não soubessem descrever a função de nenhum dos órgãos mencionados, como pode ser visto na Tabela 3.

Tabela 3: Respostas dos participantes quanto à função das partes do corpo.

\begin{tabular}{|c|c|c|}
\hline $\begin{array}{l}\text { Partes do Corpo Humano dos } \\
\text { bonecos da familia sexuada } \\
\text { para relato da função } \\
\end{array}$ & $\begin{array}{c}\text { Respostas dos participantes sobre a } \\
\text { função }\end{array}$ & $\begin{array}{c}\text { No de } \\
\text { respostas }\end{array}$ \\
\hline Vulva da menina & $\begin{array}{r}\text { Urinar ("fazer xixi") } \\
\text { Ter relações sexuais ("transar") } \\
\text { Menstruar } \\
\text { Não sabia ("não sei") }\end{array}$ & $\begin{array}{l}2 \\
1 \\
1 \\
3\end{array}$ \\
\hline Seios (mamas) da mulher adulta & $\begin{array}{r}\text { Amamentar } \\
\text { Não sabia ("não sei") }\end{array}$ & $\begin{array}{l}3 \\
2\end{array}$ \\
\hline Vulva da mulher adulta & $\begin{array}{r}\text { Urinar ("fazer xixi") } \\
\text { Menstruar } \\
\text { Ter relações Sexuais ("transar") } \\
\text { Não sabia ("não sei") } \\
\end{array}$ & $\begin{array}{l}3 \\
1 \\
2 \\
1\end{array}$ \\
\hline Pênis do menino & $\begin{array}{r}\text { Urinar ("fazer xixi") } \\
\text { Ter relações sexuais ("transar") } \\
\text { Não sabia ("não sei") } \\
\text { Engravidar }\end{array}$ & $\begin{array}{l}2 \\
1 \\
1 \\
1\end{array}$ \\
\hline Pênis do homem adulto & $\begin{array}{r}\text { Urinar ("fazer xixi") } \\
\text { Ter relações sexuais ("transar") } \\
\text { Não sabia }\end{array}$ & $\begin{array}{l}4 \\
2 \\
1\end{array}$ \\
\hline Sacos Escrotais do homem adulto & $\begin{array}{r}\text { Ter filhos } \\
\text { Armazenar espermatozóides ("segura os } \\
\text { espermatozóides") } \\
\text { Não sabia ("não sei") }\end{array}$ & $\begin{array}{l}1 \\
1 \\
3\end{array}$ \\
\hline
\end{tabular}

Observação: Leia-se nesta tabela: texto em itálico e aspas referem-se ao relato, na integra, dos participantes.

Em relação à diferença entre o corpo da menina e da mulher adulta, um participante disse não haver nenhuma; quatro, porém, afirmaram que sim, sendo estas atribuídas aos pêlos pubianos (três), ao seio (um) e ao fato de ser criança (um).

Quanto à diferença entre o corpo do menino e do homem adulto, um participante disse não haver e outro não conseguiu responder. Três afirmaram que sim, sendo estas atribuídas aos pêlos pubianos (dois) e ao fato de ser criança (um).

\section{3) Relato verbal sobre temas da sexualidade a partir das pranchas ilustrativas}

De maneira geral os jovens com deficiência mental conseguiram descrever adequadamente as cenas apresentadas, sobretudo os temas: namoro, casamento, menstruação, relação sexual, gravidez, parto e amamentação. A cena do abuso sexual para dois deles suscitou relatos tais como "fazendo tudo errado. Transar com o menino é muito errado"; "para ele olhar, tocar e pegar e o menino não quis que ele toque", embora nenhum tenha utilizado o termo 'abuso'. As cenas ligadas a 'masturbação' e 'jogos sexuais' provocaram falas diversas que, na maioria dos casos, não corresponderam especificamente ao que estava envolvido nas cenas. Os resultados podem ser vistos na Tabela 4. 
Tabela 4: Relatos dos participantes após exposição das cenas de dez temas da sexualidade

\begin{tabular}{|c|c|c|c|c|c|}
\hline \multirow{2}{*}{$\begin{array}{c}\text { Temas da } \\
\text { Sexualidade: } \\
\text { cenas } \\
\end{array}$} & \multicolumn{5}{|c|}{ Relatos dos Participantes } \\
\hline & P1 & $\mathbf{P 2}$ & $\mathbf{P 3}$ & $\mathbf{P 4}$ & $\mathbf{P 5}$ \\
\hline Namoro & $\begin{array}{r}\text { Esse tá } \\
\text { namorando }\end{array}$ & Beijando & Namorando & Namorando & Namorando \\
\hline Casamento & Casando & Casando & Casando & Casando & Casando \\
\hline Masturbação & $\begin{array}{r}\text { Tomando banho } \\
\text { e a menina ta } \\
\text { descansando }\end{array}$ & $\begin{array}{r}\text { Este ta tomando } \\
\text { banho e este } \\
\text { está sentado }\end{array}$ & $\begin{array}{r}\text { Lavando o pipi e } \\
\text { outro esfregando } \\
\text { o dedo }\end{array}$ & $\begin{array}{r}\text { Ele tá soltando } \\
\text { espermatozóide } \\
\text { Mulher } \\
\text { apaixonada por } \\
\text { um homem } \\
\end{array}$ & $\begin{array}{r}\text { Tomando banho } \\
\text { e a menina } \\
\text { lavando, ela ta } \\
\text { pondo a mão na } \\
\text { vagina }\end{array}$ \\
\hline Jogos Sexuais & $\begin{array}{r}\text { "esse aqui tá } \\
\text { fazendo xixi, } \\
\text { esse ta vendo } \\
\text { febre, } \\
\text { segurando a } \\
\text { boneça...tão na } \\
\text { praia" }\end{array}$ & "nadando" & $\begin{array}{r}\text { "fazendo xixi, } 0 \\
\text { outro enconstando } \\
\text { na } \\
\text { menina...tirando a } \\
\text { calça...brincando } \\
\text { com a boneca" }\end{array}$ & $\begin{array}{r}\text { "o menino ta } \\
\text { vendo se a } \\
\text { menina ta com } \\
\text { febre" }\end{array}$ & $\begin{array}{r}\text { "brincando na } \\
\text { piscina, salva } \\
\text { vida" }\end{array}$ \\
\hline Menstruação & $\begin{array}{r}\text { Ta pondo } \\
\text { modess }\end{array}$ & $\overline{N a ̃ o ~ s e i}$ & $\begin{array}{r}\text { Colocando } \\
\text { modess... } \\
\text { absorvente }\end{array}$ & $\begin{array}{r}\text { Colocando } \\
\text { negócio na } \\
\text { menina. Parece } \\
\text { meia, mas não é } \\
\text { E a menina ta } \\
\text { vendo }\end{array}$ & $\begin{array}{r}\text { Colocando } \\
\text { modess }\end{array}$ \\
\hline Relação Sexual & Tão transando & Não sei & Transando & Transando & Transando \\
\hline Gravidez & $\begin{array}{l}\text { Emulher } \\
\text { grávida }\end{array}$ & Não sei & $\begin{array}{r}\text { Transou e ficou } \\
\text { grávida }\end{array}$ & Esperando filho & Gravidez \\
\hline Parto & $\begin{array}{r}\text { Quando ta } \\
\text { nascendo }\end{array}$ & $\overline{N a ̃ o}$ sei & $\begin{array}{r}\text { Tirando da } \\
\text { barriga o nenê }\end{array}$ & $\begin{array}{r}\text { Retirando o } \\
\text { bebê }\end{array}$ & $\begin{array}{r}\text { Tendo nenê. } \\
\text { Cesária e parto } \\
\text { normal } \\
\end{array}$ \\
\hline Amamentação & Nenê mamando & $\begin{array}{r}\text { Um menino } \\
\text { mamando }\end{array}$ & $\begin{array}{r}\text { Mamando e } \\
\text { amamentando }\end{array}$ & $\begin{array}{r}\text { Se alimentando } \\
\text { o bebê }\end{array}$ & $\begin{array}{r}\text { Amamentan- } \\
\text { do na.mamadeira } \\
\text { e no peito }\end{array}$ \\
\hline $\begin{array}{l}\text { Abuso } \\
\text { Sexual }\end{array}$ & $\begin{array}{r}\text { Não gosta de } \\
\text { por as coisas } \\
\text { em ordem. Ele } \\
\text { não gosta de ir } \\
\text { no banheiro } \\
\text { com outro. Não } \\
\text { gosta de fazer } \\
\text { lição }\end{array}$ & Não sei & $\begin{array}{r}\text { Pipi pra fora, } \\
\text { estudando, } \\
\text { colocando no } \\
\text { banheiro. É ruim }\end{array}$ & $\begin{array}{r}\text { Fazendo tudo } \\
\text { errado. Transar } \\
\text { com menino é } \\
\text { errado }\end{array}$ & $\begin{array}{r}\text { Para ele olhar, } \\
\text { tocar e pegar e, } \\
\text { menino não quis } \\
\text { que ele toque }\end{array}$ \\
\hline
\end{tabular}

Observação: Leia-se nesta tabela: texto em itálico ao relato na íntegra dos participantes.

\section{Discussão}

Os dados evidenciam que os jovens com deficiência mental que participaram deste estudo têm noção da sua identidade sexual, isto é, se são homens e mulheres e ainda demonstram ter incorporado os papéis sexuais masculinos e femininos, o que contradiz a idéia de Gherpelli (1995) e Pinel (1999) de que as pessoas com deficiência mental têm dificuldade em adquirir uma identidade sexual e papéis sexuais coerentes com seu sexo biológico. Entretanto, os resultados corroboram o estudo de Maia (2001c).

Os participantes também mostraram conhecimento dos órgãos sexuais masculinos $\mathrm{e}$ femininos, sabendo nomeá-los, mas sem identificar, 
adequadamente, suas funções. Quando se referiram à função desses órgãos, limitaram-se à de excreção, mas sem citar procriação ou mesmo de relação sexual.

Sobre os temas investigados, alguns relatos foram coerentes e bem relacionados às figuras (pranchas), como namoro, casamento, menstruação, relação sexual, gravidez, parto, amamentação. Ainda que os jovens não façam uma fala prolongada $\mathrm{e}$ articulada, mas se expressem com frases curtas e objetivas, nestas cenas ficou evidente que a maioria tem noção do conceito ao qual o tema se referia. Em outros assuntos, no entanto, como masturbação, jogos sexuais infantis e abuso sexual, os relatos são mais gerais sem desenvolver, de fato, o tema apresentado. A hipótese é de que masturbação e jogos sexuais infantis são experiências que fazem parte do desenvolvimento da sexualidade, mas que são vigiadas e 'proibidas', especialmente para os deficientes, o que dificultaria uma explicação mais objetiva por parte deles sobre o assunto. Por outro lado, namoro, casamento, relação sexual, gravidez, parto e amamentação são temas mais comentados, divulgados e propagados na mídia, na sociedade, na família e desse modo tornam-se acessíveis à formação de um conceito, o que não acontece nos demais. Acrescente-se, inclusive, que é comum isso acontecer tanto frente a pessoas com deficiências como àquelas sem este quadro.

Os dados deste estudo permitem, pois, colocar que os jovens com deficiência mental têm informações sobre a sexualidade e são capazes de comentar a respeito, ainda que de forma limitada. A jovem (P2) foi única em apresentar a resposta "não sei" em várias pranchas (menstruação, relação sexual, gravidez, parto e abuso sexual), devendo-se lembrar que esta participante era a mais nova do grupo, com apenas 13 anos. A questão que fica, então, é que, se as pessoas com deficiência mental são alvo das informações que circulam na sociedade, porque priválas de uma orientação sexual que as informe adequadamente $\mathrm{e}$ as esclareça?

\section{Considerações Finais}

Os resultados individuais dos jovens são interessantes se tomados como exemplos, pois a amostra é limitada e não se propõe nenhuma generalização dos dados. Entretanto, considera-se que o instrumento utilizado foi bastante produtivo para estimular o relato de pessoas comprometidas intelectualmente e, com estratégias diferentes daquelas usualmente utilizadas como as entrevistas abertas e os questionários fechados, mostrou-se eficaz para explorar a dificuldade em dialogar dessa população, especialmente no caso da sexualidade, em que há escassez de recursos metodológicos para realizar a investigação.

\section{Conclui-se, portanto, que:}

- Os jovens com deficiência mental têm acesso a informações sobre sexualidade, ainda que limitadas e muitas vezes deturpadas. Isso reforça a idéia de que é necessário e urgente que propostas de orientação sexual sejam colocadas em prática como parte dos currículos educacionais junto à população especial;

- Apesar da impossibilidade de generalização dos dados, as estratégias utilizadas mostraram ser alternativas eficazes para incentivar o relato de jovens com limitação intelectual sobre temas complexos, como a sexualidade.

- Investigar estratégias viáveis junto à população especial traz contribuições relevantes se se almeja a implementação de programas de orientação sexual eficazes na área da educação especial. Portanto, outras pesquisas merecem dar continuidade a essa investigação, ampliando-se a amostra e considerando graus mais comprometidos da deficiência mental.

\section{Referências Bibliográficas}

Amaral, L. (1994). Adolescência/Deficiência: uma sexualidade adjetivada. Temas em Psicologia, 2, 75-79.

Assumpção Júnior, F. \& Sprovieri, M.H. (1993). Deficiência mental, família e sexualidade. São Paulo: Memnon.

Cavalcanti, R.C. (1990). Identidade e Papéis Sexuais. Em R.C. Cavalcanti. Saúde Sexual e 
Reprodutiva (pp.227-229). Brasília: CESEX.

Cavalcanti, R.C. (1993). Educação Sexual no Brasil e na América Latina. Revista Brasileira de

Sexualidade Humana, 4(2), 164-173.

Denari, F. (1997). $O$ adolescente especial e a sexualidade: nem anjo, nem fera.Tese de Doutorado, Universidade Federal de São Carlos, São Carlos, SP.

Duarte, R.G. (1995). Sexo, sexualidade e DST. São Paulo: Moderna.

França Ribeiro, H.C. (1995). Orientação Sexual e Deficiência Mental: estudos acerca da implementação de uma programação. Tese de Doutorado, Universidade de São Paulo, São Paulo.

França Ribeiro, H.C. (2001). Sexualidade e os Portadores de Deficiência Mental. Revista Brasileira de Educação Especial 7(2), p.11-27.

Gale, J. (1989). $O$ adolescente e o sexo - um guia para os pais. São Paulo: Best Seller.

Giami, A. \& D'Allones, C.R. (1984). O anjo e a fera: as representações da sexualidade dos deficientes mentais pelos pais e educadores. Em D. Neto (Org.), A negação da deficiência: a instituição da diversidade (pp.29-41). Rio de Janeiro: Achiamé/Socius.

Gherpelli, M.H.B.V. (1995). Diferente, mas não desigual - a sexualidade do deficiente mental. São Paulo: Gente.

Glat, R. (1992). A sexualidade da pessoa com deficiência mental. Revista Brasileira de Educação Especial 1(1), 65-74.

Glat, R. \& Freitas, R.C. (1996). Sexualidade e Deficiência Mental: pesquisando, refletindo e debatendo sobre o tema: questões atuais em Educação Especial, Vol. II. Rio de Janeiro: Sette Letras.

Lipp, M.N. (1981). Sexo para deficientes mentais: sexo e excepcional dependente e não dependente. São Paulo: Cortez.

Maia, A.C.B. (1999). A sexualidade de pessoas com deficiência mental segundo seus relatos $e$ de seus pais. Trabalho apresentado no IV Seminário de Pesquisa em Educação Especial. São

\section{Carlos:UFSCar.}

Maia, A.C.B. (2001a). Reflexões sobre a educação sexual da pessoa com deficiência. Revista Brasileira de Educação Especial 7(1), p.35-46.

Maia, A.C.B. (2001b). Sexualidade: reflexões sobre um conceito amplo. Revista da $9^{a}$ Reunião da Sociedade Brasileira de Pesquisadores Nikkeis, 5(1), p.45-48.

Maia, A.C.B. (2001c). A Sexualidade de pessoas com deficiência mental segundo seus relatos: identidade e papéis sexuais. Em M.C. Marquezine; M.A. Almeida \& E. D. O. Tanaka (Orgs.), Perspectivas Multidisciplinares em Educação Especial II (pp. 621-626). Londrina: UEL:ABEU.

Mead, M. (1988). Sexo e Temperamento. São Paulo: Perspectiva.

Money, J.; Tucker, P. (1975). Os papéis sexuais. São Paulo: Brasiliense.

Paiva, V. (1989). Evas, Marias e Lilithis: as voltas do feminismo. São Paulo: Brasiliense.

Pinel, A.C. (1999). Educação Sexual para pessoas portadoras de deficiências físicas e mentais. Em M. Ribeiro (Org.), O Prazer e o Pensar: orientação sexual para educadores e profissionais de saúde,2_(pp.211-226). São Paulo: Gente: Cores.

Ribeiro, P.R.M. (1990). Educação Sexual-além da informação. São Paulo: EPU.

Vitiello, N. (1995). A Educação Sexual Necessária. Revista Brasileira de Sexualidade Humana 6(1), 18-28.

Werebe, M.J.G. (1977). A educação sexual nas escolas. São Paulo: Moraes.

Whitaker, D.C.A. (1989). Mulher-Homem: o mito da desigualdade. São Paulo: Moderna. 